\title{
Arterial pulmonary hypertension in noncardiac intensive care unit
}

\author{
Mykola V Tsapenko 1,5 \\ Arseniy $\vee T$ sapenko ${ }^{2}$ \\ Thomas BO Comfere ${ }^{3,5}$ \\ Girish K Mour ${ }^{1,5}$ \\ Sunil V Mankad ${ }^{4}$ \\ Ognjen Gajic ${ }^{1,5}$ \\ 'Division of Pulmonary and \\ Critical Care Medicine; ${ }^{3}$ Division \\ of Critical Care Medicine; ${ }^{4}$ Division \\ of Cardiovascular Diseases, Mayo \\ Epidemiology and Translational \\ Research in Intensive Care \\ (M.E.T.R.I.C), Mayo Clinic, Rochester, \\ MN, USA; ${ }^{2}$ Division of Pulmonary \\ and Critical Care Medicine, Brown \\ University, Miriam Hospital, \\ Providence, RI, USA
}

\begin{abstract}
Pulmonary artery pressure elevation complicates the course of many complex disorders treated in a noncardiac intensive care unit. Acute pulmonary hypertension, however, remains underdiagnosed and its treatment frequently begins only after serious complications have developed. Significant pathophysiologic differences between acute and chronic pulmonary hypertension make current classification and treatment recommendations for chronic pulmonary hypertension barely applicable to acute pulmonary hypertension. In order to clarify the terminology of acute pulmonary hypertension and distinguish it from chronic pulmonary hypertension, we provide a classification of acute pulmonary hypertension according to underlying pathophysiologic mechanisms, clinical features, natural history, and response to treatment. Based on available data, therapy of acute arterial pulmonary hypertension should generally be aimed at acutely relieving right ventricular (RV) pressure overload and preventing RV dysfunction. Cases of severe acute pulmonary hypertension complicated by RV failure and systemic arterial hypotension are real clinical challenges requiring tight hemodynamic monitoring and aggressive treatment including combinations of pulmonary vasodilators, inotropic agents and systemic arterial vasoconstrictors. The choice of vasopressor and inotropes in patients with acute pulmonary hypertension should take into consideration their effects on vascular resistance and cardiac output when used alone or in combinations with other agents, and must be individualized based on patient response.
\end{abstract}

Keywords: acute pulmonary hypertension, pulmonary hypertension, acute cor pulmonale, cor pulmonale, right heart failure

\section{Introduction}

Many complex medical disorders managed in the intensive care unit (ICU) are associated with an elevation of pulmonary arterial pressure (PAP). Usually this is transient, of mild to moderate severity and not considered to affect patient outcome. However, in some circumstances serious and prolonged elevation of PAP progresses to severe acute pulmonary hypertension, leading to life threatening complications including refractory systemic arterial hypotension, severe hypoxemia, right ventricular (RV) dysfunction and failure and ultimately resulting in cardiogenic and/or obstructive shock and death. Unfortunately, in most cases acute pulmonary hypertension remains under diagnosed and its treatment begins only after serious complications have developed.

It is well known that left ventricular dysfunction/failure is one of the main causes of pulmonary venous hypertension, particularly in the cardiac ICU setting (McNeil et al 2003). However, this review is focused on the pathophysiology, monitoring and management of the acute and acute on chronic arterial pulmonary hypertension treated in the noncardiac ICU.

\section{Definition of arterial pulmonary hypertension}

Pulmonary hypertension is characterized by elevated PAP and secondary RV failure. The currently accepted clinical classification of pulmonary hypertension (World Health 
Organization [WHO] Venice 2003) distinguishes five main types of the condition (Table 1) (Galie et al 2004). However, this classification of sustained (chronic) pulmonary hypertension is less applicable in acute settings. In order to clarify the terminology of acute pulmonary hypertension and distinguish it from chronic pulmonary hypertension, we provide a classification of acute pulmonary hypertension according to underlying pathophysiologic mechanisms, clinical features, natural history, and response to treatment (Table 2).

Chronic pulmonary arterial hypertension (PAH) is defined by a mean pulmonary arterial pressure (PAP) $>25 \mathrm{mmHg}$ at rest or $>30 \mathrm{mmHg}$ with exercise, associated with a pulmonary capillary wedge pressure $(\mathrm{PCWP})<15 \mathrm{mmHg}$ and pulmonary vascular resistance $(\mathrm{PVR})>3 \mathrm{mmHg} / \mathrm{l} / \mathrm{min}$ (Wood units) measured by right heart catheterization. It is considered to be severe if mean PAP $>45 \mathrm{~mm} \mathrm{Hg}$; of moderate severity, if mean PAP 35-45 mm Hg or mild, if mean PAP $<35 \mathrm{~mm}$ $\mathrm{Hg}$. Despite clinical and pathophysiologic differences among different kinds of pulmonary hypertension, it is widely accepted to apply mean PAP definitions developed for PAH to other types of pulmonary hypertension.

Cor pulmonale is the most important consequence of pulmonary hypertension and remains a frequent cause of $\mathrm{RV}$ failure and death in patients with arterial pulmonary hypertension in the ICU. Cor pulmonale is defined as a change in structure and function of the RV, which develops as a result of a respiratory disorder or other abnormalities in the pulmonary circulation system. Almost all diseases manifested by arterial pulmonary hypertension can cause cor pulmonale: either as an acute condition, if the arterial pulmonary hypertension develops acutely (as with sepsis/acute lung injury [ALI], pulmonary embolism [PE], cardiac surgery, drug-induced, etc), or as a

Table I Clinical classification of pulmonary hypertension - Venice 2003

. Pulmonary arterial hypertension (PAH)

I.I. Idiopathic (IPAH)

I.2. Familial (FPAH)

I.3. Associated with (APAH):

I.3. I. Connective tissue disease

I.3.2. Congenital systemic to pulmonary shunts

I.3.3. Portal hypertension

I.3.4. HIV infection

1.3.5. Drugs and toxins

I.3.6. Other (thyroid disorders, glycogen storage disease, Gaucher's disease, hereditary hemorrhagic telangiectasia, hemoglobinopathies, myeloproliferative disorders, splenectomy)

I.4. Associated with significant venous or capillary involvement

I.4.I. Pulmonary veno-occlusive disease (PVOD)

I.4.2. Pulmonary capillary hemangiomatosis $(\mathrm{PCH})$

I.5. Persistent pulmonary hypertension of the newborn (PPHN)

2. Pulmonary hypertension associated with left heart diseases

2.I. Left-sided atrial or ventricular heart disease

2.2. Left-sided valvular heart disease

3. Pulmonary hypertension associated with lung respiratory diseases and/or hypoxia

3.I. Chronic obstructive pulmonary disease

3.2. Interstitial lung disease

3.3. Sleep disordered breathing

3.4. Alveolar hypoventilation disorders

3.5. Chronic exposure to high altitudes

3.6. Developmental abnormalities

\section{Pulmonary hypertension due to chronic thrombotic and/or embolic disease}

4.I.Thromboembolic obstruction of proximal pulmonary arteries

4.2. Thromboembolic obstruction of distal pulmonary arteries

4.3. Nonthrombotic pulmonary embolism (tumor, parasites, foreign material)

5. Miscellaneous (Sarcoidosis, histiocytosis X, lymphangiomatosis, compression of pulmonary vessels (adenopathy, tumor, fibrosing mediastinitis) 
Table 2 Pulmonary hypertension in the intensive care unit

- Acute and acute-on-chronic venous pulmonary hypertension

Pulmonary hypertension secondary to left ventricular dysfunction/failure with left atrial hypertension

- CHF, acute MI, diastolic dysfunction, severe valvular disease (MR, MS, etc)

- Pulmonary venoocclusive disease (VOD)

- Acute-on-chronic arterial pulmonary hypertension

Worsening of preexisting pulmonary hypertension, usually with

respiratory or cardiovascular decompensation either as

- Natural progression or

- Precipitated by acute condition (such as sepsis/ARDS, PE, drugs etc)

- Acute arterial pulmonary hypertension

Without preexisting pulmonary hypertension

- Massive PE

-ARDS, sepsis, drug-induced, etc.

Abbreviations: ARDS, acute respiratory distress syndrome; $\mathrm{CHF}$, chronic heart failure; Ml, myocardial infection; $\mathrm{MR}$, mitral regurgitation; $\mathrm{MS}$, mitral stenosis; $\mathrm{PE}$, pulmonary embolism; VOD, pulmonary veno-occlusive disease.

chronic condition, if arterial pulmonary hypertension is mainly chronic (as in chronic obstructive pulmonary disease (COPD), interstitial lung disease (ILD), sleep disorder breathing, chronic hypoventilation, $\mathrm{PAH}$, chronic thromboembolic pulmonary hypertension/CTEPH, portopulmonary hypertension etc). Increased RV afterload leads to RV dilatation in most acute cases of cor pulmonale when there is not enough time for adaptive mechanisms (eg, RV hypertrophy) to develop. Thus, RV dilatation or RV hypertrophy are the main features of the acute and chronic cor pulmonale, respectively.

\section{Pathophysiology of pulmonary hypertension}

Pathological changes in each segment of the pulmonary vasculature (precapillary arteries and arterioles, capillary beds, and postcapillary pulmonary veins and venules). can lead to the development of pulmonary hypertension. Pulmonary venous and capillary hypertension typically results from left ventricular (LV) diastolic dysfunction, valvular heart disease, or rarely, pulmonary venous disorders. The mechanisms of arterial pulmonary hypertension include vascular thromboembolism, endothelial dysfunction, (hypoxic) vasoconstriction, pulmonary vascular remodeling, smooth muscle proliferation with or without neointimal formation and in situ thrombosis (Humbert et al 2004). Endothelial dysfunction with an imbalance between vasodilation and vasoconstriction, and between apoptosis and proliferation is thought to play a pivotal role in the development of chronic progressive PAH. Hypoxemic pulmonary vasoconstriction is an important determinant of arterial pulmonary hypertension in patients with respiratory disorders (Humbert et al 2004). In many types of pulmonary hypertension production of endogenous vasodilators (nitric oxide [NO] and prostacyclin) is impaired and production of vasoconstrictors (endothelin-1) is increased (Humbert et al 2004). This forms the pathophysiologic basis of common treatment strategies for arterial pulmonary hypertension which attempt to achieve balance in key molecular pathways by increasing available $\mathrm{NO}$ and prostacyclin, or reducing the effects of endothelin-1.

Acute arterial pulmonary hypertension is characterized by a sudden increase in PAP. Mechanical obstruction with subsequent vasoconstriction characterizes acute pulmonary hypertension in PE. In ALI/acute respiratory distress syndrome (ARDS), both hypoxic pulmonary vasoconstriction and accumulation of intravascular fibrin and cellular debris contribute to subsequent vascular obliteration and pulmonary hypertension (Moloney and Evans 2003). Endotoxin plays a significant role in the development of pulmonary hypertension during sepsis. Multiple animal studies have shown that endotoxin can cause not only systemic hypotension, but also pulmonary biphasic hypertension, along with a decrease in compliance and an increase in resistance of respiratory system (Albertini et al 2001). Endotoxin-dependent hemodynamic and respiratory effects are mediated by excessive release of inflammatory mediators and imbalances in production of NO, prostanoids, and endothelin-1 (ET-1) (Wort and Evans 1999; Albertini et al 2001). Pulmonary hypertension in endotoxemia is characterized by constriction of proximal pulmonary arteries during the early phase followed by decreased compliance of the distal pulmonary vasculature (Lambermont et al 1999). Endotoxin infusion can dramatically affect RV function: in the very early phase of endotoximic shock, $\mathrm{RV}$-vascular coupling is preserved by an increase in $\mathrm{RV}$ contractility. Later, myocardial oxygen consumption and energy cost of RV contractility are increased, which along with progressive endotoxin-induced pulmonary hypertension lead to RV dysfunction and failure (Lambermont et al 2003). Maintenance of appropriate coronary perfusion is therefore an important therapeutic consideration during septic shock.

Neurohormonal activation is an important factor in both acute and chronic RV failure. The consequence of sympathetic hyperactivity is an increase in pulmonary vascular resistance (PVR) with impedance of flow, causing RV strain that impairs filling and causes RV volume and pressure overload. The RV dilates (and eventually hypertrophy 
can develop in chronic gradual pulmonary hypertension), encroaching on the LV and decreasing preload, cardiac output, and coronary perfusion. Increased RV wall stress results in RV ischemia (Via and Braschi 2004). Tricuspid regurgitation develops as a result of $\mathrm{RV}$ dysfunction and portends a poor prognosis (Nath et al 2004). RV systolic dysfunction, severe tricuspid regurgitation, arrhythmias, and LV dysfunction caused by ventricular interdependence may contribute to low cardiac output and hypotension in patients with pulmonary hypertension. Regardless of the underlying cause of pulmonary hypertension, the final common pathway for hemodynamic deterioration and death is cor pulmonale and RV failure. Among other clinically important adverse effects of right heart failure is the development of systemic venous hypertension leading to concomitant visceral organ congestion and dysfunction.

It is important to emphasize the difference between the ability of RV to adapt to sudden (acute) vs gradual (chronic) elevation of PAP. The normal RV can acutely adapt to high flow, but is not able to tolerate any but very short acute high pressure load (Blaise et al 2003). The normal RV cannot acutely increase and sustain mean PAP $>40 \mathrm{~mm} \mathrm{Hg}$ for more than a brief period of time (Chin et al 2005).

\section{Common causes of arterial pulmonary hypertension in noncardiac ICU \\ Acute on chronic arterial pulmonary hypertension}

Patients with preexisting pulmonary hypertension (ie, acute on chronic arterial pulmonary hypertension) are particularly vulnerable to acute illnesses, which commonly result in rapid deterioration and even death (Hoeper et al 2002). Besides PAH several other conditions are associated with chronic arterial pulmonary hypertension including interstitial lung diseases, COPD, chronic hypoventilation and sleep disorder breathing, portopulmonary hypertension and chronic pulmonary thromboembolism. Multiple predisposing factors (Table 3 ) can precipitate acute on chronic pulmonary hypertension and cor pulmonale and lead to adverse outcome in patients with preexisting chronic arterial pulmonary hypertension.

Patients with chronic pulmonary arterial hypertension can rapidly deteriorate and usually die from progressive RV failure (49\%), progressive respiratory failure (18\%), or sudden cardiac death (17\%). Cardiopulmonary resuscitation (CPR), even when attempted in the hospital setting is rarely
Table 3 Factors predisposing to adverse outcome in patients with preexisting pulmonary hypertension

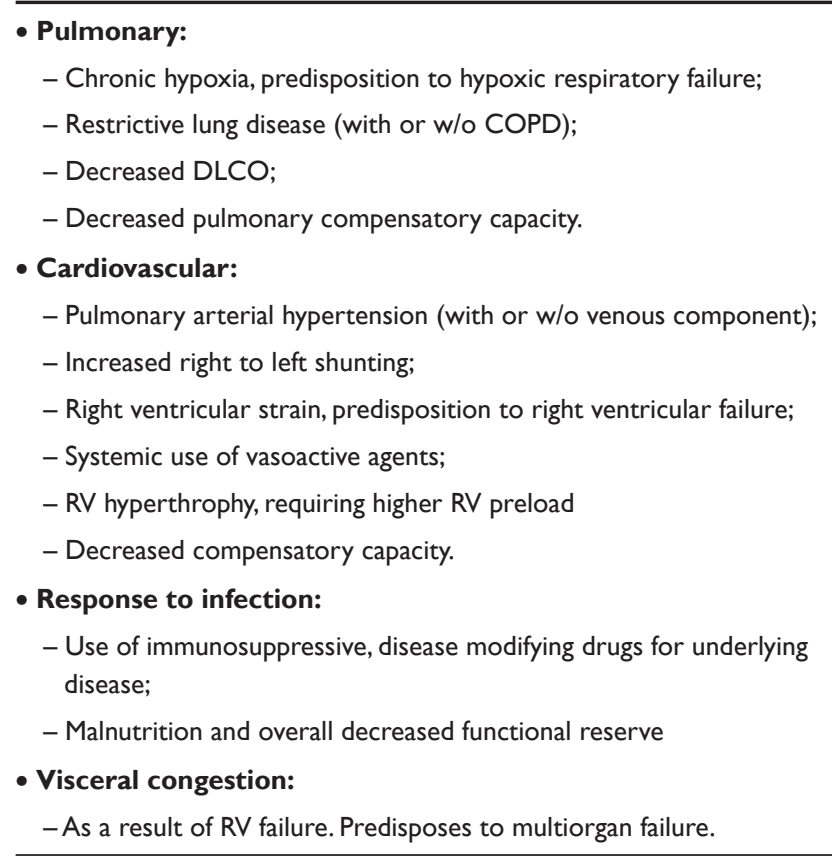

Abbreviations: COPD, chronic obstructive pulmonary disease; DLCO, diffusing capacity of the lung for carbon monoxide; $\mathrm{RV}$, right ventricle.

successful. Only $6 \%$ patients survived for more than 90 days and most survivors had identifiable causes of circulatory arrest that were rapidly reversible. The pulmonary blood flow is virtually absent in these patients during CPR (Hoeper et al 2002). Interestingly, hemodynamic measurements obtained within 3 month before CPR did not reveal any significant differences between the survivors and non survivors. In 54\%, cardiorespiratory arrest was associated with an intercurrent illness (Hoeper et al 2002), illustrating how preexisting pulmonary hypertension adversely affects patients' compensatory capacity and ability to survive an acute illness.

\section{Acute arterial pulmonary hypertension}

Massive PE, sepsis, and ALI are the main causes of acute arterial pulmonary hypertension in the adult patient population (Vieillard-Baron et al 2001b).

\section{Massive pulmonary embolism}

Massive PE involving at least two lobar arteries is the most important cause of acute cor pulmonale developing in $61 \%$ of patients with massive PE. The mortality ranges from $3 \%$ in hemodynamically stable patients to $59 \%$ in unstable patients (Kasper et al 1997; Vieillard-Baron et al 2001a).

Hemodynamic instability in a setting of PE is defined as systolic blood pressure (SBP) $<90 \mathrm{mmHg}$ or a drop in 
SBP $>40 \mathrm{mmHg}$ from baseline for more then 15 minutes, which is not otherwise explained by hypovolemia, sepsis, or new arrhythmia (Kasper et al 1997) The degree of shock inferred from the presence of metabolic acidosis, but not TTE (TransThoracic ECHO) findings is the most powerful predictor of death in these patients (Vieillard-Baron et al 2001a, 2002).

\section{Acute respiratory distress syndrome and sepsis}

The onset of acute cor pulmonale as a complication of ALI and its more severe form, ARDS, is more gradual than in patients with massive PE. It usually occurs at least 48 hours after the beginning of respiratory support (Vieillard-Baron et al 2001b).

Evaluation of RV function by TEE (TransEsophageal ECHO) in a group of 75 ARDS patients submitted to protective ventilation demonstrated $25 \%$ incidence of acute $\mathrm{RV}$ dysfunction, with detrimental hemodynamic consequences associated with tachycardia. However, those changes in heart function were reversible in patients who recovered and did not increase mortality (Vieillard-Baron et al 2001b). Although the initial magnitude of pulmonary hypertension was not an indicator of mortality, PAP further increased in nonsurvivors, but not in survivors when followed for 7 days (Leeman 1999). Thus, development of the pulmonary hypertension in ARDS patients seems to be a sign of poor prognosis. In a cohort of 352 ARDS patients both mortality rate and incidence of cor pulmonale were related to the level of plateau pressure during mechanical ventilation. An interaction between plateau pressure and cor pulmonale was observed whereas odds ratio of dying for an increase in plateau pressure (from 18-26 to $27-35 \mathrm{~cm} \mathrm{H}_{2} \mathrm{O}$ ) in patients without cor pulmonale was 1.05 $(p=0.635)$, in contrast to odds ratio of $3.32(p<0.034)$ in patients with cor pulmonale (Jardin and Vieillard-Baron 2007). The implementation of low tidal volume ventilation in patients with ARDS has significantly lowered not only mortality (down to $32 \%$ ), but also incidence of acute cor pulmonale in this patient population (Vieillard-Baron et al 2001b).

In addition to being the major risk factor for ARDS development, sepsis itself can sometimes lead to severe acute arterial pulmonary hypertension (Sibbald et al 1978).

Intra- and post-surgical pulmonary hypertension Some surgical interventions, in particular vascular, cardiac and thoracic surgery may cause acute elevation of PAP either during the surgery or shortly after the intervention has been completed. This is particularly dangerous in patients with preexisting pulmonary hypertension, since even short periods of RV pressure overload can lead to profound decompensation with all negative hemodynamic consequences. Preexisting pulmonary hypertension is one of the major risk factors for morbidity and mortality in cardiothoracic surgery patients (Bernstein and Parsonnet 2000). Pulmonary hypertension is a major determinant of perioperative morbidity and mortality in special situations such as heart and lung transplantation, pneumonectomy, and ventricular assist device placement (Subramaniam and Yared 2007).

Airway manipulations and some induction agents can precipitate an acute increase in PVR (Hickey and Retzack 1993; Hohn et al 1999). At the same time sedative/anesthetic drugs can decrease ventricular contractility (eg, barbiturates, propofol) or decrease SVR (eg, propofol) negatively affecting systemic and coronary perfusion pressure. All this can cause severe circulatory collapse, particularly in patients with preexisting pulmonary hypertension (Hohn et al 1999). It is believed that an elevated PAP during and after surgery develops secondary to acute left heart failure/dysfunction or can be a consequence of pulmonary parenchymal and endothelial injury with activation of the systemic and pulmonary inflammatory response to cardiopulmonary bypass circulation and/or ischemia-reperfusion (Wynne and Botti 2004). Protamine-mediated acute pulmonary hypertension and RV failure in the perioperative period are common (1.78\%) complications of cardiopulmonary bypass circulation during open-heart operations (Ocal et al 2005).

Pulmonary hypertension can also develop later as a result of ARDS (Milot et al 2001) or other complications (sepsis, $\mathrm{PE}$, etc) not directly related to either surgery or anesthesia.

\section{Diagnosis and monitoring of patients with pulmonary hypertension in ICU}

A high level of suspicion is the key point in establishing a timely diagnosis of acute arterial pulmonary hypertension. Clinical presentation, physical exam, electrocardiogram and chest radiography can suggest pulmonary circulation abnormality. However, those data are not specific enough to be useful in diagnosing acute pulmonary hypertension in ICU. Pulmonary hypertension is usually recognized when the patient develops obvious signs of progressive RV failure, and during hemodynamic monitoring by echocardiogram or a pulmonary artery catheterization. In many cases pulmonary hypertension remains undiagnosed and its treatment begins only after serious complications have developed. Timely 
assessment of pulmonary artery pressures, cardiac output (CO) and pulmonary vascular resistance with the help of pulmonary artery catheterization and/or echocardiography is crucial for optimal management of patients with pulmonary hypertension. The role of alternative diagnostic tests such as volumetric capnography is unclear at present (Moreira et al 2007).

\section{Pulmonary artery catheterization}

Pulmonary artery (PA) catheterization is considered a gold standard for the diagnosis of pulmonary hypertension (Chemla et al 2002) when chronic pulmonary hypertension is suspected. Besides direct measurement of the pulmonary hemodynamic parameters it also provides useful information regarding response to vasodilator therapy. Analysis of mixed venous oxygen saturations during passage of the PA catheter on its way through the cardiac chambers can allow diagnosis of intracardiac shunts. A pulmonary capillary wedge pressure (PCWP) measurement reflects left ventricular end-diastolic (filling) pressure. Values $<15 \mathrm{~mm}$ $\mathrm{Hg}$ rule out left ventricular, valvular and pulmonary venous diseases as possible causes of the pulmonary hypertension (Chemla et al 2002).

In critical care settings PA catheterization and monitoring is highly desirable in patients with severe pulmonary hypertension and in patients with progressive heart failure (Fincke et al 2004). It is important to emphasize that the thresholds required for diagnosis of severe chronic pulmonary hypertension are incompatible with life in patients with acute pulmonary hypertension and usually reflect worsening of preexisting chronic pulmonary hypertension. Although there is a little doubt that hemodynamic data are valuable in the care of critically ill patients with acute conditions complicated by pulmonary hypertension, there is no data available on how PA monitoring could affect management and outcome of these patients. Indeed, placing a PA catheter could be a challenging and dangerous procedure in such patient population. Technical difficulties could be related to severe tricuspid regurgitation, RV dilatation, elevated PAP, and decreased cardiac output. Complications of PA catheterization are particularly dangerous in patients with pulmonary hypertension and RV dysfunction/failure. Arrhythmias in response to PA catheterization can have potentially life-threatening consequences by decreasing cardiac output, or induction of fatal ventricular arrhythmias. Obtaining a PCWP may be technically difficult in patients with markedly elevated PAP, and also carries a high risk of sometimes fatal pulmonary arterial rupture. Finally, the presence of tricuspid regurgitation can significantly decrease the accuracy of cardiac output calculations by thermodilution. Theoretically, Fick's method could be more accurate, but in critically ill patients with increased pulmonary metabolism and high or very low cardiac output its accuracy may not be optimal (Caruso et al 2002).

\section{Echocardiography}

Echocardiography has become an important tool not only for screening of chronic pulmonary hypertension, but also for diagnosing and determining the degree and clinical significance of pulmonary hypertension in critically ill patients (Hoeper et al 2002; Humbert et al 2004). It can noninvasively visualize cardiac anatomy and certain intracardiac shunts and valvular abnormalities, estimate right atrial and PAP, determine the severity of right and left ventricular dysfunction, wall motion abnormalities and reveal other potential causes of pulmonary hypertension. In the absence of pulmonary outflow obstruction, pulmonary artery systolic pressure is equivalent to right ventricular systolic pressure (RVSP), which can be calculated from measured systolic regurgitant tricuspid flow velocity and estimated right atrial pressure. Pulmonary hypertension is usually defined as RVSP $>35 \mathrm{~mm} \mathrm{Hg}$ with the expected upper normal limit up to $40 \mathrm{~mm} \mathrm{Hg}$ in older or obese subjects (McQuillan et al 2001). Among 3790 healthy people who underwent echocardiography RVSP was highly variable in the range of $15-57 \mathrm{mmHg}$ and was associated with age, body mass index (BMI), gender, wall thickness, and ejection fraction. A RVSP $>40 \mathrm{~mm} \mathrm{Hg}$ was found in $6 \%$ of those $>50$ years old and $5 \%$ of those with a BMI $>30 \mathrm{~kg} / \mathrm{m}^{2}$ (McQuillan et al 2001). Therefore, not every elevation of RVSP indicates a presence a pathological condition. Possible explanations for mildly elevated RVSP detected by echocardiography include (Barst et al 2004): 1) overestimation of the RVSP in a patient with true normal pulmonary pressure; 2) serendipitous observation of a transient pressure elevation in an otherwise healthy individual; 3) discovery of stable mild pulmonary hypertension; or 4) discovery of early progressive PAH.

Echocardiographic signs of significant pulmonary hypertension include RV dilation (D-shaped right ventricle) and its hypertrophy (in sustained cases), septal dyskinesia and bowing into the LV during late systole to early diastole, RV hypokinesis, tricuspid regurgitation, right atrial enlargement, and a dilated inferior vena cava (Chemla et al 2002; Vieillard-Baron et al 2002; Bossone et al 2005). In patients with chronic PAH predictors of poor outcome include right 
atrial enlargement, septal bowing, and the development of a pericardial effusion (Raymond et al 2002).

Increased RV size combined with increased outflow resistance and reduced ejection fraction have been also described in acute cor pulmonale (Vieillard-Baron et al 2002). A specific pattern of RV dysfunction in acute pulmonary embolism has been characterized by a severe hypokinesia of the RV mid-free wall, with normal contractions of the apical segment (McConnell et al 1996).

TTE results were poorly predictive of the risk of death in patients who developed acute cor pulmonale (Lambermont et al 2003). However, definition of the acute cor pulmonale as right ventricular end-diastolic area/left ventricular end-diastolic area (RVEDA/LVEDA) ratio in the long axis greater than 0.6 associated with septal dyskinesia in the short axis could be used to stratify the severity of the condition (Vieillard-Baron et al 2001a; Engelke et al 2006).

Images may be suboptimal in critically ill patients because of limitations related to patient's general condition, limited positioning, attached monitoring devices, wound dressings, or ventilatory support. TEE may be more accurate and sensitive in critically ill patients than TTE, especially in acute diseases such as pulmonary embolism when acute pulmonary hypertension is highly suspected (Karski 2006). Newly developed handheld ultrasound devices capable of TEE may sufficiently replace a standard cart-based TEE system in unstable critically ill patients (Schneider et al 2007).

Advanced Doppler ECHO techniques allow for comprehensive hemodynamic assessment of the patients with pulmonary hypertension. A high correlation between PA catheter and Doppler echocardiography evaluations of cardiac output, transpulmonary gradient and PVR were observed in patients with severe pulmonary hypertension (Selimovic et al 2007).

\section{Troponin}

Serum troponin may be elevated in patients with pulmonary hypertension and has been associated with RV overdistension and/or ischemia. Troponin I leak due to acute right ventricular strain from pulmonary embolism has been well studied, and may predict mortality (Mehta et al 2003; La Vecchia et al 2004).

\section{Natriuratic peptides}

Elevated BNP is an important prognostic indicator and correlates strongly with PVR, cardiac output, and functional status in patients with PAH (Leuchte et al 2004).
A high level of plasma BNP, and in particular, a further increase in plasma BNP during follow-up, may have a strong, independent association with increased mortality rates in this patient population (Nagaya et al 2000). However, the significance of measuring BNP level in patients with pulmonary hypertension in the acute setting remains unclear.

\section{Management of arterial pulmonary hypertension in noncardiac ICU} General management principles Acute on chronic pulmonary hypertension

Patients with chronic pulmonary hypertension usually have multiple predisposing factors (Table 3), which make them more vulnerable to acute conditions and explain decreased ability to survive acute illness (Hoeper et al 2002). Tighter monitoring combined with early diagnosis and appropriate intervention increases the chance of survival. Treatment strategies for such patients should be generally directed at rapid reversal of the precipitating condition as well as at relieving $\mathrm{RV}$ pressure overload and maintaining systemic pressure for coronary and end organ perfusion. Unlike patients with acute pulmonary hypertension (Chin et al 2005), patients who develop acute pulmonary hypertension on top of preexisting pulmonary hypertension can generate higher pulmonary arterial pressure and also require higher RV preload (because of RV hypertrophy).

\section{Massive pulmonary embolism}

Therapy for acute massive pulmonary embolism with associated hemodynamic instability or cardiogenic/obstructive shock aims at urgently relieving mechanical obstruction of the pulmonary circulation by either pharmacologic thrombolysis or by surgical or catheter thrombectomy (or mechanical clot disruption) (Buller et al 2004; Yoshida et al 2006). Patients with massive PE but without hemodynamic instability are less likely to benefit from thrombolytic therapy. The time the resolution of RV dilatation, which usually takes between 10 and 20 days, is hastened by thrombolytic therapy (Vieillard-Baron et al 2001a).

\section{Pulmonary hypertension associated with ARDS and sepsis}

The therapy of acute pulmonary hypertension in patients with sepsis and ARDS is generally aimed at optimizing gas exchange and minimizing ventilator induced lung injury. Inhaled pulmonary vasodilators are sometimes used in order to prevent or relieve acute cor pulmonale. 


\section{Pulmonary vasodilators}

Ability to produce sustained pulmonary vasodilation is not the only factor affecting the decision to choose particular vasodilator in treatment of acute pulmonary hypertension. Route of administration, half-life and systemic effects should also be considered. Vasodilators administered intravenously may decrease PVR, but they also have longer half lives and affect systemic circulation. A decrease in systemic mean arterial pressure may result in reduced right coronary blood flow and further deterioration of $\mathrm{RV}$ performance. Inhalation of pulmonary vasodilators can improve ventilation/perfusion (V/Q) matching by reaching and subsequently vasodilating only well ventilated areas of the lung. Inhaled pulmonary vasodilators with a short half-life and no systemic vasodilation effect are considered a treatment of choice for acute arterial pulmonary hypertension.

\section{Inhaled NO}

Inhaled NO (INO) is a potent vasodilator that dilates pulmonary vasculature in ventilated lung areas, thereby improving V/Q match and oxygenation, and reducing PAP (Pepke-Zaba et al 1991) and RV oxygen demand (Zwissler et al 1995). This improves cardiac performance without altering RV contractility (Cockrill et al 2001) and cardiac output in hemodynamically stable patients with a variety of causes of pulmonary hypertension (Fierobe et al 1995; Bhorade et al 1999). INO has a very short half-life and almost no systemic vasodilatory effects, which is very important in treatment of hemodynamically unstable patients. While underlying causes of RV failure and baseline hemodynamics did not predict response to INO, the use of alpha-agonist catecholamines did (Bhorade et al 1999).

Multiple studies on utilization of the INO in ARDS patients showed improved oxygenation for 24-48 hours, variable improvement in mean PAP (McIntyre et al 1995) and no significant impact on the duration of ventilatory support or mortality in this patient population (Kaisers et al 2003; Taylor et al 2004). A combination of INO and other interventions, such as positive end-expiratory pressure and prone positioning, yielded beneficial and additive effects on arterial oxygenation (Kaisers et al 2003). INO has been successfully used and associated with improved outcomes in critically ill postoperative patients, who developed severe pulmonary hypertension or RV failure (Della Rocca and Coccia 2005; George et al 2006).

A combination treatment of INO with other pulmonary vasodilators (milrinone, sildenafil etc) has been used in management of acute pulmonary hypertension in different conditions (Deb et al 2000; Lepore et al 2005b). INO treatment is associated with multiple side effects including methemoglobinemia (Pepke-Zaba et al 1991; Troncy et al 1997) and $\mathrm{NO}_{2}$ formation (Troncy et al 1997). Abrupt withdrawal of NO has been associated with rebound pulmonary hypertension, significant drop in $\mathrm{PaO}_{2}$ and life-threatening hemodynamic deterioration (Troncy et al 1997; Christenson et al 2000). Close monitoring and gradual discontinuation is important to prevent and detect rebound pulmonary hypertension.

\section{Prostaglandins}

Prostaglandin $\mathrm{E}_{1}$ and prostacyclin both produce significant pulmonary vasodilatation and can lower PVR. Both possess antithrombotic, antiproliferative and anti-inflammatory properties. In patients with chronic severe pulmonary hypertension, intravenous prostacyclin is highly effective and associated with a significant survival benefit (McLaughlin et al 1998, 2002). Prostacyclin, subcutaneous or intravenous treprostinil, intravenous $\mathrm{PGE}_{1}$ and other prostanoids have relatively long half-lives and can significantly affect systemic hemodynamics. This feature limits their use in critically ill or hemodynamically unstable patients. Intravenous prostacyclin $\left(\mathrm{PGI}_{2}\right)$ in combination with norepinephrine and dopamine was effective in the treatment of protamine-mediated acute pulmonary hypertension and RV failure in the setting of open heart surgery (Ocal et al 2005).

Prostacyclin and its analogs (iloprost and treprostinil) in inhaled forms are as effective as intravenous forms in patients with chronic pulmonary hypertension (GombergMaitland and Olschewski 2008). In the ICU setting inhaled prosaglandins have been used to treat severe sustained pulmonary hypertension and intractable hypoxia, but were associated with systemic hypotension (Hache et al 2001). Inhaled iloprost effectively decreased pulmonary artery pressure and improved RV performance immediately after separation from cardiopulmonary bypass (Theodoraki et al 2002). Inhaled iloprost was effective in the treatment of acute RV dysfunction in the setting of pre-existing pulmonary hypertension in heart transplant recipients during weaning from cardiopulmonary bypass circulation and was not associated with significant systemic side-effects.

Despite the observation that $\mathrm{RV}$ ejection fraction increased on INO, but not with $\mathrm{PGI}_{2}$, both INO and $\mathrm{PGI}_{2}$-aerosol showed beneficial effects on RV performance and may prove helpful in the treatment of acute pulmonary hypertension (Zwissler et al 1995). Inhaled prostacyclin showed different effect on oxygenation and pulmonary hemodynamics in patients 
presenting with primary pulmonary ARDS (reduction in $\mathrm{PaO}_{2} / \mathrm{FIO}_{2}$ ) compared with extrapulmonary cause of ARDS (increase in $\mathrm{PaO}_{2} / \mathrm{FIO}_{2}$ along with a decrease in mean PAP) (Domenighetti et al 2001).

\section{Milrinone}

Milrinone is a selective phosphodiesterase-3 inhibitor with significant inotropic and vasodilatory effects for both pulmonary and systemic vasculatures. It is widely used alone or in combinations in patients with decompensated heart failure, particularly in those with nonischemic left ventricular systolic dysfunction (Mehra et al 1997; elker et al 2003) and cardiac surgery patients (Levy et al 2002; Lee et al 2006). In animal models of both acute and chronic pulmonary hypertension, milrinone significantly reduced PVR and improved RV function (Chen et al 1997; Hashiba et al 2000). In cardiac surgery patients with a history of pulmonary hypertension, INO was associated with lower heart rates, higher right ventricular ejection fraction, and a lower requirement for treatment with vasopressor agents compared to milrinone (Solina et al 2000).

The systemic vasodilatory effect of milrinone along with relatively long half life is the major limiting factors against its utilization in conditions associated with systemic hypotension or hemodynamic instability. However, in combination with INO, milrinone produced additive pulmonary vasodilatation in animal model of acute pulmonary hypertension (Deb et al 2000). A combination of milrinone and sildenafil led to more effective pulmonary vasodilation and increased $\mathrm{RV}$ contractility, without additional systemic vasodilatation in an animal model. CO and RV performance were significantly improved after milrinone or both drugs combined, but not with sildenafil alone (Lobato et al 2006). Systemic vasopressors, both norepinephrine and low dose vasopressin were effective in the treatment of milrinone-induced systemic hypotension. However, milrinone-vasopressin combination was associated with better hemodynamics than milrinonenorepinephrine during the management of right heart failure (Jeon et al 2006). In a volume-resuscitated pediatric patient with septic shock, when administered in addition to catecholamines, milrinone improved cardiovascular function (Barton et al 1996).

In an animal model of drug-induced pulmonary hypertension nebulization of milrinone failed to deliver sufficient amount of milrinone for producing a detectable hemodynamic effect (Gelvez et al 2004), but in animals with induced CHF inhalation of milrinone predominantly dilated pulmonary blood vessels, resulting in a reduced pulmonary-to-systemic vascular resistance ratio and improvement of pulmonary venous hypertension (Hentschel et al 2007). At the same time, in animals after cardiopulmonary bypass inhaled milrinone produced adequate hemodynamic and oxygenation profiles, and prevented the occurrence of the pulmonary endothelial dysfunction. (Lamarche et al 2005).

\section{Sildenafil and other phosphodiesterase- 5 inhibitors}

Sildenafil is a specific phosphodiesterase-5 inhibitor with sustained pulmonary vasodilatatory effect. Sildenafil lowers PVR, PAP, and increases CO in patients with different forms of chronic pulmonary hypertension (Michelakis et al 2002; Mikhail et al 2004) including patients with pulmonary hypertension secondary to congestive heart failure (Lepore et al 2005b). This effect is mainly achieved by balancing pulmonary and systemic vasodilation. In patients after coronary artery bypass graft surgery sildenafil may improve myocardial perfusion, reduce platelet activation, and potentially reduce early graft occlusion (Fung et al 2005). In the chronic setting it is highly effective both alone and in combination with other pulmonary vasodilators: epoprostenol (Stiebellehner et al 2003), iloprost (Ghofrani et al 2002, 2003), brain natriuretic peptide (BNP) (Klinger et al 2006), and inhaled NO (Lepore et al 2005b). Although mostly used in patients with chronic pulmonary hypertension and in hemodynamically stable patients sildenafil possesses multiple features that could be effective in treatment of critically ill patients with severe RV dysfunction related to secondary pulmonary hypertension ( $\mathrm{Ng}$ et al 2005). Its ability to augment and prolong the hemodynamic effects of other pulmonary vasodilators has been successfully used to minimize rebound pulmonary hypertension after INO discontinuation (Atz and Wessel 1999; Trachte et al 2005; Namachivayam et al 2006), weaning from intravenous vasodilators in patients after cardiac surgery (Trachte et al 2005) as well as in chronic PAH therapy (Johnson et al 2007).

Experimental evaluation of the inhaled and intravenous sildenafil administration showed similar effects on pulmonary endothelium-dependent relaxation, overall hemodynamic profile and oxygenation after cardiopulmonary bypass. Both administration routes prevented a significant increase in mean PAP without severe systemic hypotension (Aubin et al 2008).

Two other specific phosphodiesterase-5 inhibitors: zaprinars and dipyridamole seem to be potentially very effective in the management of acute pulmonary hypertension. Administration of either of these drugs leads to dose-dependent pulmonary vasodilation and no significant systemic arterial 
hypotension (Matot and Gozal 2004). Intravenous zaprinast may increase the efficacy and prolong the duration of action of INO. However, its efficacy in lung injury models was uncertain: nonselective vasodilation induced by intravenously administered zaprinast not only worsens gas exchange, but also abolishes the beneficial effects of INO (Adrie et al 2000). Subthreshold doses (which do not reduce PAP) of specific phosphodiesterase-5 inhibitors (zaprinast and sildenafil) when used in acute lung injury (ALI) associated with pulmonary hypertension improved responsiveness to NO (Klein et al 2007). Dipyridamole effectively slows the progression of hypoxemic pulmonary hypertension in patients with COPD (Nenci et al 1988). In an animal model of acute pulmonary hypertension, IV dipyridamole in combination with INO decreased pulmonary artery pressure for a prolonged period of time and reduced exposure to NO (Foubert et al 2003). Dipyridamole can lower PVR, augment INO-induced pulmonary vasodilation, acutely attenuate the adverse hemodynamic effects of rapid withdrawal of INO therapy (Ivy et al 1998), and attenuate excessive hypoxic pulmonary vasoreactivity (Ziegler et al 1998). In pediatric patients with pulmonary hypertension dipyridamole decreased PVR index to similar values as INO did, but with significant systemic vasodilatation (Ziegler et al 1998). Intravenous dipyridamole has been used to identify reversibility of pulmonary hypertension in potential cardiac transplant recipients with $\mathrm{CHF}$ in whom a pulmonary vasodilator response to inhalation of $\mathrm{NO}$ alone is not observed (Lepore et al 2005a). Intravenous dipyridamole was also used in acute management of pulmonary hypertension in combination either with INO or intravenous nitroglycerin (Sulica et al 2005).

\section{Natriuretic peptides}

Natriuretic peptides (atrial natriuretic peptide [ANP] and brain natriuretic peptide [BNP]) in addition to their diuretic, vasorelaxing, and hemodynamic effects are able to inhibit vascular smooth-muscle proliferation and cardiac hypertrophy, as well as counteract the renin-angiotensin system (Krupicka et al 2008). ANP and BNP produced dose-related pulmonary vasodilatation in patients with cor pulmonale, without worsening oxygen saturation or affecting systemic hemodynamics and exerted favorable neurohormonal effects by suppressing aldosterone (Cargill and Lipworth 1996). Although both ANP and BNP exhibit pulmonary vasorelaxing activity, only BNP significantly attenuated the mean PAP and acute hypoxic pulmonary vasoconstriction in otherwise healthy individuals (Cargill and Lipworth 1995). BNP alone had no effect on mean PAP or PVR in patients with PAH, but was well tolerated and augmented the acute pulmonary vasodilator effect of sildenafil (Klinger et al 2006). Nesiritide acutely and significantly reduced PA pressure, PVR, and biventricular filling pressures in patients with postcapillary pulmonary hypertension. However, in patients with precapillary pulmonary hypertension, it had no significant acute hemodynamic effect on the pulmonary hemodynamics (Michaels et al 2005). Use of nesiritide in hemodynamically unstable and hypotensive patients is limited, mainly because of reduction of systemic vascular resistance and resulting profound systemic hypotension (Yancy et al 2007).

\section{Other pulmonary vasodilators}

Nitroprusside and nitroglycerin both can cause significant pulmonary vasodilation similar to that of INO. However, nitroprusside has a longer half life and can cause acute reduction of systemic vascular resistance leading to systemic hypotension associated with a decrease in RV contractility, limiting its use in hemodynamically unstable and hypotensive patients (Cockrill et al 2001). A significant venodilator effect of nitroglycerine decreases RV preload leading to adverse consequences in patients with right heart failure. Inhaled nitroglycerin may be a safer therapeutic option leading to a significant reduction in both mean PAP and PVR in patients after mitral valve operations without reducing systemic mean arterial pressure (Yurtseven et al 2003).

Intravenous adenosine is a pulmonary vasodilator with a very short half-life (6-10 sec.) and can be effective for short term lowering PVR (McLaughlin et al 1998). In the setting of acute pulmonary hypertension adenosine infusion may help lower PAP without lowering systemic arterial pressure and reverse the clinical state of shock by achieving pulmonary vasodilatation (Fullerton et al 1996). However, higher doses (70 $\mathrm{mg} / \mathrm{kg}$ per min to $100 \mathrm{mg} / \mathrm{kg}$ per $\mathrm{min}$ ) cause systemic vasodilation (Stobierska-Dzierzek et al 2001). Adenosine is used to treat persistent pulmonary hypertension of the newborn ( $\mathrm{Ng}$ et al 2004; Motti et al 2006).

Calcium channel blockers have been used in hemodynamically stable patients with PAH who demonstrated pulmonary vascular response to acute vasodilator challenge (Badesch et al 2007). There are no studies of calcium channel blockers in critically ill patients with acute pulmonary hypertension. Acute administration of nifedipine did not cause pulmonary vasodilation, and in contrast led to increased RVEDP and decreased RV contractility (Cockrill et al 2001). Prolonged half-life and negative inotropic effects, which may precipitate fatal worsening of RV failure, limit the use of calcium channel blockers in treatment of acute pulmonary hypertension. 
Endothelin receptor antagonists appear to be highly effective in treatment PAH in outpatient settings (Badesch et al 2007). They have not been studied in acute care settings. In an animal model pre-treatment with bosentan completely abolished endotoxin-induced acute pulmonary hypertension and changes in pulmonary compliance and resistance (Albertini et al 2001). Currently the only possible implication in critically ill patients would be weaning or conversion from inhaled or intravenous pulmonary vasodilators to oral medication (bosentan) (Johnson et al 2007).

\section{Vasopressors and inotropic agents}

Critically ill patients with associated acute pulmonary hypertension frequently develop profound and refractory systemic arterial hypotension. In cases with severe acute arterial pulmonary hypertension (eg, massive PE) relieving the acute obstruction (either mechanically or with pulmonary vasodilators) of the pulmonary circulation can successfully resolve systemic arterial hypotension. In acute pulmonary hypertension associated with decreased cardiac contractility and/or systemic vascular resistance (SVR) the use of vasopressors with or without pulmonary vasodilators is necessary to maintain coronary and end organ perfusion. Progression of RV failure should be always considered in the management plan. Cases of severe acute pulmonary hypertension combined with heart failure and systemic arterial hypotension require tight hemodynamic monitoring and aggressive treatment with combinations of pulmonary vasodilators, inotropic agents and systemic arterial vasoconstrictors. The choice of vasopressor and inotropes in patients with acute pulmonary hypertension should take into consideration their effects on PVR and cardiac output when used alone or in combinations with other agents, and must be individualized based on individual patient response. Most traditional vasopressors and inotropes have not been studied in the setting of severe acute arterial pulmonary hypertension and hemodynamic instability.

Dobutamine is the most studied inotropic agent in patients with pulmonary hypertension. Administration of dobutamine augments myocardial contractility and reduces left ventricular afterload. It can cause systemic hypotension in some patients because of peripheral vasodilatory effects, which may require use of norepinephrine or other peripheral vasoconstrictors to maintain appropriate systemic perfusion pressures. In low doses (up to $5 \mu \mathrm{g} / \mathrm{kg} / \mathrm{min}$ ) dobutamine decreased PVR, lowered MAP and slightly increased cardiac output (Bradford et al 2000); at doses of 5-10 $\mu \mathrm{g} / \mathrm{kg}$ per min, dobutamine caused significant tachycardia and systemic hypotension without improving PVR (Bradford et al 2000; Kerbaul et al 2004). In combination with INO dobutamine administration had additive effects on pulmonary circulation (Bradford et al 2000), increased cardiac performance and improved oxygenation (P/F patio) (Vizza et al 2001) with no effect on systemic hemodynamics. In an animal model of acute RV failure secondary to acute pulmonary hypertension, dobutamine was superior to norepinephrine in improving RV function by optimizing pulmonary vasodilation, decreasing PA resistance and elastance and increasing RV contractility (Kerbaul et al 2004).

Norepinephrine has significant inotropic effects and produces vasoconstriction. It is widely used in critical care settings to treat hemodynamically unstable patients. In addition to positive effects on cardiac output and systemic arterial pressure, norepinephrine increases PVR and worsens pulmonary artery hypertension (Kwak et al 2002). However, norepeinephrine is superior to phenylephrine in restoring systemic arterial pressure, decreasing PVR, augmenting right ventricular myocardial blood flow and improving cardiac output in animal model of acute PE (Hirsch et al 1991). Alfa-adrenergic stimulation can cause a disproportionate rise in PVR (Brimioulle et al 1997) which is implicated in the development of acute pulmonary hypertension in critical illnesses. Besides disproportional a increase in PVR phenylephrine also causes bradycardia (Tisdale et al 1995) with detrimental consequences on pulmonary and systemic hemodynamic.

The effects of phenylephrine and norepinephrine in the treatment of systemic hypotension were evaluated in patients with chronic pulmonary hypertension who developed systemic hypotension following induction of anesthesia. In contrast to phenylephrine norepinephrine decreased the ratio of pulmonary arterial pressure to systemic blood pressure without a change in cardiac index. Thus, norepinephrine has been considered to be preferable to phenylephrine for the treatment of hypotension in patients with chronic pulmonary hypertension (Kwak et al 2002). There is growing data (as we have partially presented earlier) on successful combination of norepinephrine and selective pulmonary vasodilators in the treatment of patients with acute and chronic pulmonary hypertension (Tritapepe et al 1999).

Dopamine produces dose dependent dopaminergic, betaand alpha-adrenergic effects on cardiac output and vascular tone. In patients with chronic pulmonary hypertension dopamine infusion led to increased heart rate, mean PAP, aortic mean pressure, and cardiac index with concomitant fall of systemic vascular resistance (Holloway et al 1975). Administration 
of dopamine, similar to epinephrine, is associated with high risk of tachyarrhythmia, with potentially fatal consequences in patients with severe pulmonary hypertension (Tisdale et al 1995). In a small animal study of sepsis-induced pulmonary hypertension epinephrine infusion increased SVR and cardiac output and lowered PVR (Meadow et al 1986). There is no other supportive data on use epinephrine in patients with chronic or acute pulmonary hypertension.

Isoproterenol has positive inotropic and chronotropic effect, which in therapeutic doses increases cardiac output and produces pulmonary and peripheral vasodilation. As a pulmonary vasodilator, isoproterenol is one of the preferred inotropic agents in heart transplantation patients with elevated PVR. The dosage of isoproterenol should be reduced gradually because PVR may return quickly to elevated baseline levels after discontinuation of this drug (Stobierska-Dzierzek et al 2001). In animals with acute pulmonary hypertension administration of isoproterenol did not reduce PAP, and instead produced significant tachycardia and was associated with arrhythmias (Prielipp et al 1991).

Vasopressin is an endogenous hormone with weak nonadrenergic vasopressor effect on the systemic vasculature and an ability to produce NO mediated selective pulmonary vasodilation (Evora et al 1993). In healthy animals a linear relationship was observed between vasopressin levels and systemic vascular resistance. However, vasopressin did not affect PVR or any vascular compliance (Wallace et al 1989). It was very effective (at dose of $0.1 \mathrm{U} / \mathrm{min}$ ) in treating refractory low SVR hypotension concomitant with pulmonary hypertension in postoperative patients (Tayama et al 2007). Experimental data on use of vasopressin in acute pulmonary hypertension is controversial: In one setting of acute pulmonary vasoconstriction vasopressin infusion produced significant pulmonary vasodilation (Trempy et al 1994). Use of high dose of vasopressin (1.16 units $/ \mathrm{kg} / \mathrm{h})$ in another animal model of acute pulmonary hypertension led to increased PVR and decreased cardiac output with a decrease in RV contractility, leading the authors to cautioning against its use when RV function is compromised (Leather et al 2002) .

Experimental data suggest that levosimendan (a myocardial and vascular calcium sensitizer) has pulmonary vasodilatory properties which, in combination with its positive inotropic effects, would render it particularly attractive for the treatment of RV dysfunction related to acute pulmonary hypertension. In a model of acute right ventricular dysfunction, levosimendan improved global hemodynamics and optimized right ventriculo-vascular coupling via a moderate increase in RV contractility and a mild reduction of RV afterload (Missant et al 2007). A similar effect was achieved in an animal model of progressive pulmonary hypertension and RV failure related to recurrent pulmonary embolism (Kerbaul et al 2007). In those settings levosimendan restored $\mathrm{RV}$ function better than dobutamine because of similar inotropic effects and additional pulmonary vasodilatory effects (Kerbaul et al 2004) Levosimendan was successfully combined with milrinone in one study (Stocker et al 2007). A pilot prospective, randomized study on patients with ARDS in association with septic shock showed that levosimendan improves right ventricular performance mainly through pulmonary vasodilator effects (Morelli et al 2006).

\section{Fluid management}

Experiments in 1983 showed that when RV afterload is increased, even a relatively small increase in preload may result in RV dysfunction. RV dysfunction occurred with volume expansion, despite constant PVR and a decrease in mean PAP. This and further observations draw the conclusion that high RV filling pressure restores normal hemodynamics only if PVR is normal and RV contractility is not markedly reduced (Via and Braschi, 2004).

In patients with pulmonary hypertension, RV dysfunction/failure can reduce LV filling and lead to cardiogenic shock. Patients with cardiogenic shock secondary to RV dysfunction usually have a very high $(>20 \mathrm{~mm} \mathrm{Hg}) \mathrm{RV}$ filling pressure (Jacobs et al 2003). In addition to decreased RV contractility and cardiac output RV dilatation can further limit LV filling via ventricular interdependence, which causes shifting of the interventricular septum toward the LV cavity. Following the traditional paradigm that RV failure is treated with aggressive fluid resuscitation can, thus, worsen the patient's condition. The challenge in fluid management in those patients is to find the optimal RV preload necessary to avoid the detrimental effects of ventricular interdependence on LV function. Hemodynamic monitoring of patients with $\mathrm{RV}$ failure due to acute RV myocardial infarction showed that cardiac and stroke indexes increased and the RV reached its maximum stroke work index when the filling pressure was 10-14 mm Hg. These values may be regarded as the optimal level of RV filling pressure in patients with RV infarction (Berisha et al 1990). There is no data on optimal RV filling pressure in patients with RV dysfunction secondary to acute pulmonary hypertension.

\section{Ventilator management}

It was found that controlled ventilation altered RV function primarily by increasing $\mathrm{RV}$ afterload during the lung 
inflation period (Jardin et al 1990). Transpulmonary pressure (and related tidal volume), but not airway pressure itself, was the main determinant factor of RV afterload during mechanical ventilation (Vieillard-Baron et al 1999). This supports a low-volume strategy in ARDS, recommended as a protective measure for lung parenchyma, which might also represent a protective measure for the RV and pulmonary circulation (Vieillard-Baron et al 1999). Frequency of acute cor pulmonale in ARDS patients declined from $61 \%$ to $25 \%$ over the last 15-30 years, which could be explained in part by fundamental alterations in respiratory support and implementation low tidal volume ventilation (Vieillard-Baron et al 2001b). Lower incidence of acute cor pulmonale in ARDS patients was associated with lower (less then $27-30 \mathrm{mmHg}$ ) plateau pressure (Jardin and Vieillard-Baron 2007).

RV systolic function was generally negatively affected by end-expiratory pressure (PEEP) in ARDS patients undergoing mechanical ventilation. In those patients PEEP titration significantly affected RV outflow impedance, the lowest values of which was associated with the achieved better total quasi-static lung compliance (calculated by dividing tidal volume by the difference between plateau and end-expiratory airway pressures) (Schmitt et al 2001). This suggests that lung hyperinflation along with either inadequate or excessive PEEP can significantly reduce RV systolic function and cardiac output. On other hand, in an experimental study on healthy animals, the open lung concept ventilation resulted in significantly improved lung aeration with no negative effect on RV afterload or LV afterload. This is possibly explained by a loss of hypoxic pulmonary vasoconstriction due to alveolar recruitment. The reductions in the $\mathrm{CO}$ and in the mean PAP were the consequences of a reduced preload (Miranda et al 2006). A clinical study in patients after cardiac surgery found no evidence that ventilation according to the open lung concept affects RV afterload (Reis Miranda et al 2004).

Hypercapnia has been shown to induce pulmonary hypertension in animal models. There is no data on how it could affect acute pulmonary hypertension in humans. However, study on healthy volunteers revealed that human pulmonary vascular responses to hypercapnia and hypocapnia consist, respectively, of constriction and dilatation that take $1.5-2 \mathrm{~h}$ to reach a steady level. The time courses for recovery in eucapnia are similar. Hypercapnia generated a rise in cardiac output by changing heart rate; hypocapnia produced a fall in cardiac output by changing stroke volume. The finding of marked vasodilatation in response to hypocapnia demonstrates that there is normally a substantial vascular tone in the human pulmonary circulation (Balanos et al 2003).
Treatment with $100 \%$ oxygen is a selective pulmonary vasodilator in patients with sustained pulmonary hypertension, regardless of primary diagnosis, baseline oxygenation, or right ventricular function (Roberts et al 2001). In patients with ALI vascular response to oxygen was different and administration of $100 \% \mathrm{O}_{2}$ worsened intrapulmonary shunt possibly secondary to collapse of unstable alveolar units with very low ventilation-perfusion $(\mathrm{V} \mathrm{A} / \mathrm{Q})$ ratios. This is in contrast to administration of $100 \% \mathrm{O}_{2}$ to patients with COPD, in whom only the dispersion of the blood flow distribution was changed, suggesting release of hypoxic pulmonary vasoconstriction (Santos et al 2000). Optimal supplemental oxygen management is an integral component of pulmonary hypertension therapy in the ICU (Zamanian et al 2007).

\section{Other treatment options}

The observations of a survival advantage in patients with pulmonary hypertension and a patent foramen ovale suggested that an intra-atrial right-to-left shunt could decompress the RV and increase LV pre-load, thereby increasing systemic blood flow and improving systemic oxygen transport despite arterial oxygen desaturation. Atrial septostomy has been developed as an alternative/bridge treatment and applied in patients with lack of response to medical therapy in the absence of other surgical treatment options. It has a substantial morbidity and mortality in critically ill patients with severe RV failure (Sandoval et al 2001). With growing experience, procedure-related death rates have been reduced to $5.4 \%$, and the most suitable patient group has been identified among patients with a mean right atrial pressure between 10 and $20 \mathrm{~mm} \mathrm{Hg}$ (Klepetko et al 2004). Acute right heart failure after orthotopic heart transplantation was successfully managed by decompression of the RV through the patent foramen ovale of the donor heart and inhalation of iloprost (Ozdogan et al 2008). Both pericardiectomy and creation of atrial septal defects have been used in extreme cases of acute RV failure secondary to acute MI (Reynolds and Hochman, 2008). Decompression of the RV through the septostomy may potentially be an effective alternative in the management of severe acute pulmonary hypertension in ICU setting. The defect could be subsequently closed using a transcatheter septal occlusion device, after the patient's condition has been stabilized.

In cases of acute right heart failure after heart transplantation, mechanical circulatory support systems, such as RV assist devices, extracorporeal membrane oxygenation, femoral vein-to-femoral artery roller or centrifugal pumps, may facilitate hemodynamic stability until the transplanted 
heart has recovered, or until a new heart has been found for retransplantation (Aubert et al 2006). They possibly could be successfully applied in other cases of potentially reversible acute pulmonary hypertension and cor pulmonale. Intra-aortic balloon counterpulsation (IABP) has long been the mainstay of mechanical therapy for cardiogenic shock. Not every patient has a hemodynamic response to IABP (Reynolds and Hochman, 2008). However, in patients with acute pulmonary hypertension and RV failure associated with systemic hypotension it could improve coronary and peripheral perfusion and augment LV performance with an acute decrease in afterload (Arafa et al 2000).

\section{Conclusion}

Many complex medical disorders managed in noncardiac ICUs are associated with an elevation of PAP. In some circumstances serious and prolonged elevation of PAP progresses to severe acute pulmonary hypertension, leading to life threatening complications including refractory systemic arterial hypotension, severe hypoxemia, RV dysfunction and failure and ultimately resulting in cardiogenic and/or obstructive shock and death. Unfortunately, in most cases acute pulmonary hypertension remains under diagnosed and its treatment begins only after serious complications have developed.

Significant pathophysiologic differences between acute and chronic pulmonary hypertension made current treatment recommendations for chronic pulmonary hypertension difficult to apply to acute pulmonary hypertension. Based on available data, therapy of acute arterial pulmonary hypertension should be generally aimed at acutely relieving RV pressure overload by decreasing PVR and preventing or reversing $\mathrm{RV}$ dysfunction with pulmonary vasodilators and inotropes. Cases of severe acute pulmonary hypertension combined with developing heart failure and systemic arterial hypotension are real clinical challenges requiring tight hemodynamic monitoring and aggressive treatment including combinations of pulmonary vasodilators, inotropic agents and systemic arterial vasoconstrictors (see Figure 1). The choice of vasopressor and inotropes in patients with acute pulmonary hypertension should take in consideration their effects on PVR and cardiac output when used alone or in combinations with other agents, and must be individualized based on individual patient response.

Our review revealed significant gaps in basic science knowledge, clinical studies and management recommendations

\section{Therapeutic Approach to Arterial Pulmonary Hypertension in ICU}

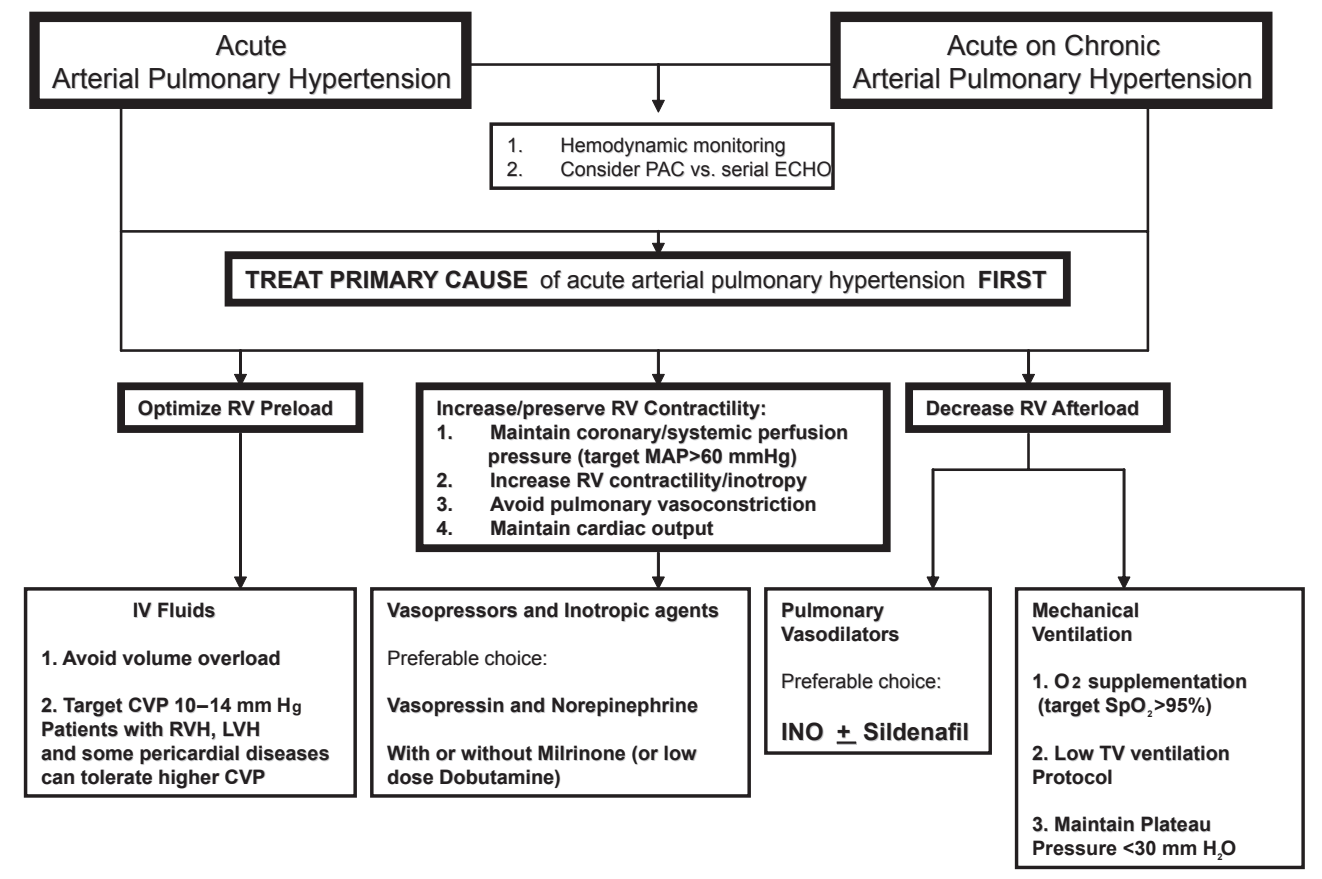

Figure I Therapeutic approach to arterial pulmonary hypertension in ICU.

Abbreviations: CVP, central venous pressure; ECHO, echocardiogram; INO, inhaled nitric oxide; IV, intravenous; LVH, left ventricular hypertrophy; MAP, mean arterial pressure; $\mathrm{PAC}$, pulmonary artery catheter; $\mathrm{RV}$, right ventricle; $\mathrm{RVH}$, right ventricular hypertrophy; $\mathrm{SpO}_{2}$, oxygen saturation in the blood; TV, tidal volume. 
for acute arterial pulmonary hypertension in the critically ill. Intensivists need to be aware of acute pulmonary hypertension in critical conditions, the importance of its early recognition and appropriate treatment.

\section{Disclosure}

Dr. Gajic's work is supported by National Institutes of Health HL78743-01A1 grant. The authors report no conflicts of interest in this work.

\section{References}

Adrie C, Holzmann A, Hirani WM, et al. 2000. Effects of intravenous Zaprinast and inhaled nitric oxide on pulmonary hemodynamics and gas exchange in an ovine model of acute respiratory distress syndrome. Anesthesiology, 93:422-30.

Albertini M, Ciminaghi B, Mazzola S, et al. 2001. Improvement of respiratory function by bosentan during endotoxic shock in the pig. Prostaglandins Leukot Essent Fatty Acids, 65:103-8.

Arafa OE, Geiran OR, Andersen K, et al. 2000. Intraaortic balloon pumping for predominantly right ventricular failure after heart transplantation. Ann Thorac Surg, 70:1587-93.

Atz AM, Wessel DL. 1999. Sildenafil ameliorates effects of inhaled nitric oxide withdrawal. Anesthesiology, 91:307-10.

Aubert S, Leprince P, Bonnet N, et al. 2006. Limited mechanical circulatory support following orthotopic heart transplantation. Interact Cardiovasc Thorac Surg, 5:88-9.

Aubin MC, Laurendeau S, Mommerot A, et al. 2008. Differential effects of inhaled and intravenous sildenafil in the prevention of the pulmonary endothelial dysfunction due to cardiopulmonary bypass. $J$ Cardiovasc Pharmacol, 51:11-7.

Badesch DB, Abman SH, Simonneau G, et al. 2007. Medical therapy for pulmonary arterial hypertension: updated ACCP evidence-based clinical practice guidelines. Chest, 131:1917-28.

Balanos GM, Talbot NP, Dorrington KL, et al. 2003. Human pulmonary vascular response to $4 \mathrm{~h}$ of hypercapnia and hypocapnia measured using Doppler echocardiography. J Appl Physiol, 941543-51.

Barst RJ, McGoon M, Torbicki A, et al. 2004. Diagnosis and differential assessment of pulmonary arterial hypertension. $\mathrm{J} \mathrm{Am} \mathrm{Coll} \mathrm{Cardiol,}$ 43(12 Suppl S):40S-47S.

Barton P, Garcia J, Kouatli A, et al. 1996. Hemodynamic effects of i.v. milrinone lactate in pediatric patients with septic shock. A prospective, double-blinded, randomized, placebo-controlled, interventional study. Chest, 109:1302-12.

Berisha S, Kastrati A, Goda A, et al. 1990. Optimal value of filling pressure in the right side of the heart in acute right ventricular infarction. Br Heart J, 63:98-102.

Bernstein AD, Parsonnet V. 2000. Bedside estimation of risk as an aid for decision-making in cardiac surgery. Ann Thorac Surg, 69:823-8.

Bhorade S, Christenson J, O'Connor M, et al. 1999. Response to inhaled nitric oxide in patients with acute right heart syndrome. Am J Respir Crit Care Med, 159:571-9.

Blaise G, Langleben D, Hubert B. 2003. Pulmonary arterial hypertension: pathophysiology and anesthetic approach. Anesthesiology, 99:1415-32.

Bossone E, Bodini BD, Mazza A, et al. 2005. Pulmonary arterial hypertension: the key role of echocardiography. Chest, 127:1836-43.

Bradford KK, Deb B, Pearl RG. 2000. Combination therapy with inhaled nitric oxide and intravenous dobutamine during pulmonary hypertension in the rabbit. J Cardiovasc Pharmacol, 36:146-51.

Brimioulle S, Vachiery JL, Brichant JF, et al. 1997. Sympathetic modulation of hypoxic pulmonary vasoconstriction in intact dogs. Cardiovasc Res, 34:384-92.
Buller HR, Agnelli G, Hull RD, et al. 2004. Antithrombotic therapy for venous thromboembolic disease: the Seventh ACCP Conference on Antithrombotic and Thrombolytic Therapy. Chest, 126(3 Suppl):401S-28S.

Cargill RI, Lipworth BJ. 1995. Acute effects of ANP and BNP on hypoxic pulmonary vasoconstriction in humans. Br J Clin Pharmacol, 40:585-90.

Cargill RI, Lipworth BJ. 1996. Atrial natriuretic peptide and brain natriuretic peptide in cor pulmonale. Hemodynamic and endocrine effects. Chest, 110:1220-5.

Caruso LJ, Layon AJ, Gabrielli A. 2002. What is the best way to measure cardiac output? Who cares, anyway? Chest, 122:771-4.

Chemla D, Castelain V, Herve P, et al. 2002. Haemodynamic evaluation of pulmonary hypertension. Eur Respir J, 20:1314-31.

Chen EP, Bittner HB, Davis RD, Jr., et al. 1997. Milrinone improves pulmonary hemodynamics and right ventricular function in chronic pulmonary hypertension. Ann Thorac Surg, 63:814-21.

Chin KM, Kim NH, Rubin RJ. 2005. The right ventricle in pulmonary hypertension. Coron Artery Dis, 16:13-8.

Christenson J, Lavoie A, O'Connor M, et al. 2000. The incidence and pathogenesis of cardiopulmonary deterioration after abrupt withdrawal of inhaled nitric oxide. Am J Respir Crit Care Med, 161:1443-9.

Cockrill BA, Kacmarek RM, Fifer MA, et al. 2001. Comparison of the effects of nitric oxide, nitroprusside, and nifedipine on hemodynamics and right ventricular contractility in patients with chronic pulmonary hypertension. Chest, 119:128-36.

Deb B, Bradford K, Pearl RG. 2000. Additive effects of inhaled nitric oxide and intravenous milrinone in experimental pulmonary hypertension. Crit Care Med, 28:795-9.

Della Rocca G, Coccia C. 2005. Nitric oxide in thoracic surgery. Minerva Anestesiol, 71:313-18.

Domenighetti G, Stricker H, Waldispuehl B. 2001. Nebulized prostacyclin (PGI2) in acute respiratory distress syndrome: impact of primary (pulmonary injury) and secondary (extrapulmonary injury) disease on gas exchange response. Crit Care Med, 29:57-62.

Engelke C, Rummeny E, Marten K. 2006. [Acute pulmonary embolism: prediction of cor pulmonale and short-term patient survival from assessment of cardiac dimensions in routine multidetector-row CT]. Rofo, 178:999-1006.

Evora PR, Pearson PJ, Schaff HV. 1993. Arginine vasopressin induces endothelium-dependent vasodilatation of the pulmonary artery. V1-receptor-mediated production of nitric oxide. Chest, 103:1241-5.

Felker GM, Benza RL, Chandler AB, et al. 2003. Heart failure etiology and response to milrinone in decompensated heart failure: results from the OPTIME-CHF study. J Am Coll Cardiol, 41:997-1003.

Fierobe L, Brunet F, Dhainaut JF, et al. 1995. Effect of inhaled nitric oxide on right ventricular function in adult respiratory distress syndrome. $\mathrm{Am}$ J Respir Crit Care Med, 151:1414-9.

Fincke R, Hochman JS, Lowe AM, et al. Cardiac power is the strongest hemodynamic correlate of mortality in cardiogenic shock: a report from the SHOCK trial registry. J Am Coll Cardiol, 44:340-8.

Foubert L, De Wolf D, Reyntjens K, et al. 2003. Intermittent nitric oxide combined with intravenous dipyridamole in a piglet model of acute pulmonary hypertension. Anesth Analg, 97:1497-500.

Fullerton DA, Jaggers J, Jones SD, et al. 1996. Adenosine for refractory pulmonary hypertension. Ann Thorac Surg, 62:874-7.

Fung E, Fiscus RR, Yim AP, et al. 2005. The potential use of type-5 phosphodiesterase inhibitors in coronary artery bypass graft surgery. Chest, 128:3065-73.

Galie N, Torbicki A, Barst R, et al. 2004. Guidelines on diagnosis and treatment of pulmonary arterial hypertension. The Task Force on Diagnosis and Treatment of Pulmonary Arterial Hypertension of the European Society of Cardiology. Eur Heart J, 25:2243-78.

Gelvez J, Fakioglu H, Olarte JL, et al. 2004. Effect of aerosolized milrinone during drug-induced pulmonary hypertension in lambs. Pharmacol Res, 50:87-91.

George I, Xydas S, Topkara VK, et al. 2006. Clinical indication for use and outcomes after inhaled nitric oxide therapy. Ann Thorac Surg, 82:2161-9. 
Ghofrani HA, Rose F, Schermuly RT, et al. 2002. Combination therapy with oral sildenafil and inhaled iloprost for severe pulmonary hypertension. Ann Intern Med, 136:515-22.

Ghofrani HA, Wiedemann R, Rose F, et al. 2003. Oral sildenafil as long-term adjunct therapy to inhaled iloprost in severe pulmonary arterial hypertension. J Am Coll Cardiol, 42:158-64.

Gomberg-Maitland M, Olschewski H. 2008. Prostacyclin therapies for the treatment of pulmonary arterial hypertension. Eur Respir J, 31:891-901.

Hache M, Denault AY, Belisle S, et al. 2001. Inhaled prostacyclin (PGI2) is an effective addition to the treatment of pulmonary hypertension and hypoxia in the operating room and intensive care unit. Can J Anaesth, 48:924-9.

Hashiba E, Hirota K, Yoshioka H, et al. 2000. Milrinone attenuates serotonininduced pulmonary hypertension and bronchoconstriction in dogs. Anesth Analg, 90:790-4.

Hentschel T, Yin N, Riad A, et al. 2007. Inhalation of the phosphodiesterase3 inhibitor milrinone attenuates pulmonary hypertension in a rat model of congestive heart failure. Anesthesiology, 106:124-31.

Hickey PR, Retzack SM. 1993. Acute right ventricular failure after pulmonary hypertensive responses to airway instrumentation: effect of fentanyl dose. Anesthesiology, 78:372-6.

Hirsch LJ, Rooney MW, Wat SS, et al. 1991. Norepinephrine and phenylephrine effects on right ventricular function in experimental canine pulmonary embolism. Chest, 100:796-801.

Hoeper MM, Galie N, Murali S, et al. 2002. Outcome after cardiopulmonary resuscitation in patients with pulmonary arterial hypertension. Am J Respir Crit Care Med, 165:341-4.

Hohn L, Schweizer A, Morel DR, et al. 1999. Circulatory failure after anesthesia induction in a patient with severe primary pulmonary hypertension. Anesthesiology, 91:1943-5.

Holloway EL, Polumbo RA, Harrison DC. 1975. Acute circulatory effects of dopamine in patients with pulmonary hypertension. Br Heart $J$, 37:482-5.

Humbert M, Morrell NW, Archer SL, et al. 2004. Cellular and molecular pathobiology of pulmonary arterial hypertension. J Am Coll Cardiol, 43(12 Suppl S):13S-24S.

Ivy DD, Kinsella JP, Ziegler JW, et al. 1998. Dipyridamole attenuates rebound pulmonary hypertension after inhaled nitric oxide withdrawal in postoperative congenital heart disease. J Thorac Cardiovasc Surg, 115:875-82.

Jacobs AK, Leopold JA, Bates E, et al. 2003. Cardiogenic shock caused by right ventricular infarction: a report from the SHOCK registry. $J \mathrm{Am}$ Coll Cardiol, 41:1273-9.

Jardin F, Delorme G, Hardy A, et al. 1990. Reevaluation of hemodynamic consequences of positive pressure ventilation: emphasis on cyclic right ventricular afterloading by mechanical lung inflation. Anesthesiology, 72:966-70.

Jardin F, Vieillard-Baron A. 2007. Is there a safe plateau pressure in ARDS? The right heart only knows. Intensive Care Med, 33:444-7.

Jeon Y, Ryu JH, Lim YJ, et al. 2006. Comparative hemodynamic effects of vasopressin and norepinephrine after milrinone-induced hypotension in off-pump coronary artery bypass surgical patients. Eur J Cardiothorac Surg, 29:952-6.

Johnson RF, Loyd JE, Mullican AL, et al. 2007. Long-term follow-up after conversion from intravenous epoprostenol to oral therapy with bosentan or sildenafil in 13 patients with pulmonary arterial hypertension. J Heart Lung Transplant, 26:363-9.

Kaisers U, Busch T, Deja M, et al. 2003. Selective pulmonary vasodilation in acute respiratory distress syndrome. Crit Care Med, 31(4 Suppl): S337-42.

Karski JM. 2003. Transesophageal echocardiography in the intensive care unit. Semin Cardiothorac Vasc Anesth, 10:162-6.

Kasper W, Konstantinides S, Geibel A, et al. 1997. Management strategies and determinants of outcome in acute major pulmonary embolism: results of a multicenter registry. J Am Coll Cardiol, 30:1165-71.
Kerbaul F, Gariboldi V, Giorgi R, et al. 2007. Effects of levosimendan on acute pulmonary embolism-induced right ventricular failure. Crit Care Med, 35:1948-54.

Kerbaul F, Rondelet B, Motte S, et al. 2004. Effects of norepinephrine and dobutamine on pressure load-induced right ventricular failure. Crit Care Med, 32:1035-40.

Klein A, Zils U, Bopp C, et al. 2007. Low-dose phosphodiesterase inhibition improves responsiveness to inhaled nitric oxide in isolated lungs from endotoxemic rats. J Surg Res, 138:224-30.

Klepetko W, Mayer E, Sandoval J, et al. 2004. Interventional and surgical modalities of treatment for pulmonary arterial hypertension. $\mathrm{J} \mathrm{Am} \mathrm{Coll}$ Cardiol, 43(12 Suppl S):73S-80S.

Klinger JR, Thaker S, Houtchens J, et al. 2006. Pulmonary hemodynamic responses to brain natriuretic peptide and sildenafil in patients with pulmonary arterial hypertension. Chest, 129:417-25.

Krupicka J, Janota T, Kasalova Z, et al. 2008. Natriuretic peptidesphysiology, pathophysiology and clinical use in heart failure. Physiol Res, Apr 1. [Epub ahead of print].

Kwak YL, Lee CS, Park YH, et al. 2002. The effect of phenylephrine and norepinephrine in patients with chronic pulmonary hypertension. Anaesthesia, 57:9-14.

La Vecchia L, Ottani F, Favero L, et al. 2004. Increased cardiac troponin I on admission predicts in-hospital mortality in acute pulmonary embolism. Heart, 90:633-7.

Lamarche Y, Malo O, Thorin E, et al. 2005. Inhaled but not intravenous milrinone prevents pulmonary endothelial dysfunction after cardiopulmonary bypass. J Thorac Cardiovasc Surg, 130:83-92.

Lambermont B, Ghuysen A, Kolh P, et al. 1999. Analysis of endotoxin effects on the intact pulmonary circulation. Cardiovasc Res, 41:275-81.

Lambermont B, Kolh P, Detry O, et al. 2003. Effects of endotoxic shock on right ventricular systolic function and mechanical efficiency. Cardiovasc Res, 59:412-18.

Leather HA, Segers P, Berends N, et al. 2002. Effects of vasopressin on right ventricular function in an experimental model of acute pulmonary hypertension. Crit Care Med, 30:2548-52.

Lee JH, Oh YJ, Shim YH, et al. 2006. The effect of milrinone on the right ventricular function in patients with reduced right ventricular function undergoing off-pump coronary artery bypass graft surgery. J Korean Med Sci, 21:854-8.

Leeman M. 1999. Pulmonary hypertension in acute respiratory distress syndrome. Monaldi Arch Chest Dis, 54:146-9.

Lepore JJ, Dec GW, Zapol WM, et al. 2005. Combined administration of intravenous dipyridamole and inhaled nitric oxide to assess reversibility of pulmonary arterial hypertension in potential cardiac transplant recipients. J Heart Lung Transplant, 24:1950-6.

Lepore JJ, Maroo A, Bigatello LM, et al. 2005. Hemodynamic effects of sildenafil in patients with congestive heart failure and pulmonary hypertension: combined administration with inhaled nitric oxide. Chest, 127:1647-53.

Leuchte HH, Holzapfel M, Baumgartner RA, et al. 2004. Clinical significance of brain natriuretic peptide in primary pulmonary hypertension. $J$ Am Coll Cardiol, 43:764-70.

Levy JH, Bailey JM, Deeb GM. 2002. Intravenous milrinone in cardiac surgery. Ann Thorac Surg, 73:325-30.

Lobato EB, Beaver T, Muehlschlegel J, et al. 2006. Treatment with phosphodiesterase inhibitors type III and V: milrinone and sildenafil is an effective combination during thromboxane-induced acute pulmonary hypertension. Br J Anaesth, 96:317-22.

Matot I, Gozal Y. 2004. Pulmonary responses to selective phosphodiesterase5 and phosphodiesterase-3 inhibitors. Chest, 125:644-51.

McConnell MV, Solomon SD, Rayan ME, et al. 1996. Regional right ventricular dysfunction detected by echocardiography in acute pulmonary embolism. Am J Cardiol, 78:469-73.

McIntyre RC, Jr., Moore FA, Moore EE, et al. 1995. Inhaled nitric oxide variably improves oxygenation and pulmonary hypertension in patients with acute respiratory distress syndrome. J Trauma, 39:418-25. 
McLaughlin VV, Genthner DE, Panella MM, et al. 1998. Reduction in pulmonary vascular resistance with long-term epoprostenol (prostacyclin) therapy in primary pulmonary hypertension. $N$ Engl J Med, 338:273-7.

McLaughlin VV, Shillington A, Rich S. 2002. Survival in primary pulmonary hypertension: the impact of epoprostenol therapy. Circulation, 106:1477-82.

McNeil K, Dunning J, Morrell NW. 2003. The pulmonary physician in critical care. 13: the pulmonary circulation and right ventricular failure in the ITU. Thorax, 58:157-62.

McQuillan BM, Picard MH, Leavitt M, et al. 2001. Clinical correlates and reference intervals for pulmonary artery systolic pressure among echocardiographically normal subjects. Circulation, 104:2797-802.

Meadow WL, Rudinsky BF, Strates E. 1986. Selective elevation of systemic blood pressure by epinephrine during sepsis-induced pulmonary hypertension in piglets. Pediatr Res, 20:872-5.

Mehra MR, Ventura HO, Kapoor C, et al. 1997. Safety and clinical utility of long-term intravenous milrinone in advanced heart failure. $\mathrm{Am} \mathrm{J}$ Cardiol, 80:61-4.

Mehta NJ, Jani K, Khan IA. 2003. Clinical usefulness and prognostic value of elevated cardiac troponin I levels in acute pulmonary embolism. Am Heart J, 145:821-5.

Michaels AD, Chatterjee K, De Marco T. 2005. Effects of intravenous nesiritide on pulmonary vascular hemodynamics in pulmonary hypertension. $J$ Card Fail, 11:425-31.

Michelakis E, Tymchak W, Lien D, et al. 2002. Oral sildenafil is an effective and specific pulmonary vasodilator in patients with pulmonary arterial hypertension: comparison with inhaled nitric oxide. Circulation, 105:2398-403.

Mikhail GW, Prasad SK, Li W, et al. 2004. Clinical and haemodynamic effects of sildenafil in pulmonary hypertension: acute and mid-term effects. Eur Heart J, 25:431-6.

Milot J, Perron J, Lacasse Y, et al. 2001. Incidence and predictors of ARDS after cardiac surgery. Chest, 119:884-8.

Miranda DR, Klompe L, Cademartiri F, et al. 2006. The effect of open lung ventilation on right ventricular and left ventricular function in lunglavaged pigs. Crit Care, 10:R86.

Missant C, Rex S, Segers P, et al. 2007. Levosimendan improves right ventriculovascular coupling in a porcine model of right ventricular dysfunction. Crit Care Med, 35:707-15.

Moloney ED, Evans TW. 2003. Pathophysiology and pharmacological treatment of pulmonary hypertension in acute respiratory distress syndrome. Eur Respir J, 21:720-7.

Moreira MM, Terzi RG, Vieira RW, et al. 2007. Pre- and post-pulmonary thromboendarterectomies capnographic variables. Rev Bras Cir Cardiovasc, 22:509-12.

Morelli A, Teboul JL, Maggiore SM, et al. 2006. Effects of levosimendan on right ventricular afterload in patients with acute respiratory distress syndrome: a pilot study. Crit Care Med, 34:2287-93.

Motti A, Tissot C, Rimensberger PC, et al. 2006. Intravenous adenosine for refractory pulmonary hypertension in a low-weight premature newborn: a potential new drug for rescue therapy. Pediatr Crit Care Med, 7:380-2.

Nagaya N, Nishikimi T, Uematsu M, et al. 2000. Plasma brain natriuretic peptide as a prognostic indicator in patients with primary pulmonary hypertension. Circulation, 102:865-70.

Namachivayam P, Theilen U, Butt WW, et al. 2006. Sildenafil prevents rebound pulmonary hypertension after withdrawal of nitric oxide in children. Am J Respir Crit Care Med, 174:1042-7.

Nath J, Foster E, Heidenreich PA. 2004. Impact of tricuspid regurgitation on long-term survival. J Am Coll Cardiol, 43:405-9.

Nenci GG, Berrettini M, Todisco T, et al. 1988. Effects of dipyridamole on the hypoxemic pulmonary hypertension of patients with chronic obstructive pulmonary disease. Respiration, 53:13-9.

$\mathrm{Ng} \mathrm{C}$, Franklin O, Vaidya M, et al. 2004. Adenosine infusion for the management of persistent pulmonary hypertension of the newborn. Pediatr Crit Care Med, 5:10-13.
Ng J, Finney SJ, Shulman R, et al. 2005. Treatment of pulmonary hypertension in the general adult intensive care unit: a role for oral sildenafil? Br J Anaesth, 94:774-7.

Ocal A, Kiris I, Erdinc M, et al. 2005. Efficiency of prostacyclin in the treatment of protamine-mediated right ventricular failure and acute pulmonary hypertension. Tohoku J Exp Med, 207:51-8.

Ozdogan ME, Erer D, Iriz E, et al. 2008. Right-to-left shunt through a patent foramen ovale left open in the management of acute right heart failure after heart transplantation. J Heart Lung Transplant, 27:135-7.

Pepke-Zaba J, Higenbottam TW, Dinh-Xuan AT, et al. 1991. Inhaled nitric oxide as a cause of selective pulmonary vasodilatation in pulmonary hypertension. Lancet, 338:1173-4.

Prielipp RC, McLean R, Rosenthal MH, et al. 1991. Hemodynamic profiles of prostaglandin E1, isoproterenol, prostacyclin, and nifedipine in experimental porcine pulmonary hypertension. Crit Care Med, 19:60-7.

Raymond RJ, Hinderliter AL, Willis PW, et al. 2002. Echocardiographic predictors of adverse outcomes in primary pulmonary hypertension. J Am Coll Cardiol, 39:1214-19.

Reis Miranda D, Gommers D, Struijs A, et al. 2004. The open lung concept: effects on right ventricular afterload after cardiac surgery. Br J Anaesth, 93:327-32.

Reynolds HR, Hochman JS. 2008. Cardiogenic shock: current concepts and improving outcomes. Circulation, 117:686-97.

Roberts DH, Lepore JJ, Maroo A, et al. 2001. Oxygen therapy improves cardiac index and pulmonary vascular resistance in patients with pulmonary hypertension. Chest, 120:1547-55.

Sandoval J, Rothman A, Pulido T. 2001. Atrial septostomy for pulmonary hypertension. Clin Chest Med, 22:547-60.

Santos C, Ferrer M, Roca J, et al. 2000. Pulmonary gas exchange response to oxygen breathing in acute lung injury. Am J Respir Crit Care Med, 161:26-31.

Schmitt JM, Vieillard-Baron A, Augarde R, et al. 2001. Positive endexpiratory pressure titration in acute respiratory distress syndrome patients: impact on right ventricular outflow impedance evaluated by pulmonary artery Doppler flow velocity measurements. Crit Care Med, 29:1154-8.

Schneider C, Schwemmer U, Kredel M, et al. 2007. Handheld vs conventional transesophageal echocardiography in non-cardiac surgical intensive care unit patients. Ultraschall Med, Aug 3. [Epub ahead of print].

Selimovic N, Rundqvist B, Bergh CH, et al. 2007. Assessment of pulmonary vascular resistance by Doppler echocardiography in patients with pulmonary arterial hypertension. J Heart Lung Transplant, 26:927-34.

Sibbald WJ, Paterson NA, Holliday RL, et al. 1978. Pulmonary hypertension in sepsis: measurement by the pulmonary arterial diastolic-pulmonary wedge pressure gradient and the influence of passive and active factors. Chest, 73:583-91.

Solina A, Papp D, Ginsberg S, et al. 2000. A comparison of inhaled nitric oxide and milrinone for the treatment of pulmonary hypertension in adult cardiac surgery patients. J Cardiothorac Vasc Anesth, 14:12-17.

Stiebellehner L, Petkov V, Vonbank K, et al. 2003. Long-term treatment with oral sildenafil in addition to continuous IV epoprostenol in patients with pulmonary arterial hypertension. Chest, 123:1293-5.

Stobierska-Dzierzek B, Awad H, Michler RE. 2001. The evolving management of acute right-sided heart failure in cardiac transplant recipients. $J$ Am Coll Cardiol, 38:923-31.

Stocker CF, Shekerdemian LS, Norgaard MA, et al. 2007. Mechanisms of a reduced cardiac output and the effects of milrinone and levosimendan in a model of infant cardiopulmonary bypass. Crit Care Med, $35: 252-9$.

Subramaniam K, Yared JP. 2007. Management of pulmonary hypertension in the operating room. Semin Cardiothorac Vasc Anesth, 11:119-36.

Sulica R, Dinh HV, Dunsky K, et al. 2005. The acute hemodynamic effect of IV nitroglycerin and dipyridamole in patients with pulmonary arterial hypertension: comparison with IV epoprostenol. Congest Heart Fail, 11:139-44; quiz 145-6. 
Tayama E, Ueda T, Shojima T, et al. 2007. Arginine vasopressin is an ideal drug after cardiac surgery for the management of low systemic vascular resistant hypotension concomitant with pulmonary hypertension. Interact Cardiovasc Thorac Surg, 6:715-19.

Taylor RW, Zimmerman JL, Dellinger RP, et al. 2004. Low-dose inhaled nitric oxide in patients with acute lung injury: a randomized controlled trial. JAMA, 291:1603-9.

Theodoraki K, Rellia P, Thanopoulos A, et al. 2002. Inhaled iloprost controls pulmonary hypertension after cardiopulmonary bypass. Can J Anaesth, 49:963-7.

Tisdale JE, Patel RV, Webb CR, et al. 1995. Proarrhythmic effects of intravenous vasopressors. Ann Pharmacother, 29:269-81.

Trachte AL, Lobato EB, Urdaneta F, et al. 2005. Oral sildenafil reduces pulmonary hypertension after cardiac surgery. Ann Thorac Surg, 79:194-7.

Trempy GA, Nyhan DP, Murray PA. 1994. Pulmonary vasoregulation by arginine vasopressin in conscious, halothane-anesthetized, and pentobarbital-anesthetized dogs with increased vasomotor tone. Anesthesiology, 81:632-40.

Tritapepe L, Voci P, Cogliati AA, et al. Successful weaning from cardiopulmonary bypass with central venous prostaglandin E1 and left atrial norepinephrine infusion in patients with acute pulmonary hypertension. Crit Care Med, 27:2180-3.

Troncy E, Francoeur M, Blaise G. Inhaled nitric oxide: clinical applications, indications, and toxicology. Can J Anaesth, 44:973-88.

Via G, Braschi A. 2004. Pathophysiology of severe pulmonary hypertension in the critically ill patient. Minerva Anestesiol, 70:233-7.

Vieillard-Baron A, Loubieres Y, Schmitt JM, et al. 1999. Cyclic changes in right ventricular output impedance during mechanical ventilation. J Appl Physiol, 87:1644-50.

Vieillard-Baron A, Page B, Augarde R, et al. 2001a. Acute cor pulmonale in massive pulmonary embolism: incidence, echocardiographic pattern, clinical implications and recovery rate. Intensive Care Med, 27:1481-6.

Vieillard-Baron A, Prin S, Chergui K, et al. 2002. Echo-Doppler demonstration of acute cor pulmonale at the bedside in the medical intensive care unit. Am J Respir Crit Care Med, 166:1310-19.
Vieillard-Baron A, Schmitt JM, Augarde R, et al. 2001b. Acute cor pulmonale in acute respiratory distress syndrome submitted to protective ventilation: incidence, clinical implications, and prognosis. Crit Care Med, 29:1551-5.

Vizza CD, Rocca GD, Roma AD, et al. 2001. Acute hemodynamic effects of inhaled nitric oxide, dobutamine and a combination of the two in patients with mild to moderate secondary pulmonary hypertension. Crit Care, 5:355-61.

Wallace AW, Tunin CM, Shoukas AA. 1989. Effects of vasopressin on pulmonary and systemic vascular mechanics. Am J Physiol, 257(4 Pt 2):H1228-34.

Wort SJ, Evans TW. 1999. The role of the endothelium in modulating vascular control in sepsis and related conditions. Br Med Bull, $55: 30-48$

Wynne R, Botti M. 2004. Postoperative pulmonary dysfunction in adults after cardiac surgery with cardiopulmonary bypass: clinical significance and implications for practice. Am J Crit Care, 13:384-93.

Yancy CW, Krum H, Massie BM, et al. 2007. The Second Follow-up Serial Infusions of Nesiritide (FUSION II) trial for advanced heart failure: study rationale and design. Am Heart J, 153:478-84.

Yoshida M, Inoue I, Kawagoe T, et al. 2006. Novel percutaneous catheter thrombectomy in acute massive pulmonary embolism: rotational bidirectional thrombectomy (ROBOT). Catheter Cardiovasc Interv, 68:112-17.

Yurtseven N, Karaca P, Kaplan M, et al. 2003. Effect of nitroglycerin inhalation on patients with pulmonary hypertension undergoing mitral valve replacement surgery. Anesthesiology, 99:855-8.

Zamanian RT, Haddad F, Doyle RL, et al. 2007. Management strategies for patients with pulmonary hypertension in the intensive care unit. Crit Care Med, 35:2037-50.

Ziegler JW, Ivy DD, Wiggins JW, et al. 1998. Effects of dipyridamole and inhaled nitric oxide in pediatric patients with pulmonary hypertension. Am J Respir Crit Care Med, 158(5 Pt 1):1388-95.

Zwissler B, Welte M, Messmer K. 1995. Effects of inhaled prostacyclin as compared with inhaled nitric oxide on right ventricular performance in hypoxic pulmonary vasoconstriction. J Cardiothorac Vasc Anesth, 9:283-9. 